\title{
Maternal hypothyroidism in the rat influences placental and liver glycogen stores: fetal growth retardation near term is unrelated to maternal and placental glucose metabolic compromise
}

\author{
M R Pickard, A J Leonard, L M Ogilvie, P R Edwards, I M Evans, \\ A K Sinha and R P Ekins \\ Division of Molecular Endocrinology, University College London Medical School, Mortimer Street, London W1T 3AA, UK \\ (Requests for offprints should be addressed to A K Sinha; Email: arun.sinha@ucl.ac.uk)
}

\begin{abstract}
Maternal hypothyroidism impairs fetal growth in the rat, but the mechanisms by which this occurs are unknown. Since the fetus derives its glucose supply from the mother, and maternal thyroidectomy may disturb maternal and placental glucose metabolism, we postulated that maternal and/or placental glucose metabolic compromise may contribute to fetal growth retardation in hypothyroid dams. Feto-placental growth, tissue glycogen stores and glucose levels in sera and amniotic fluid were determined in rat dams partially thyroidectomized (TX) before pregnancy and in euthyroid controls. Fetal body weight at 16, 19 and 21 days gestation (d.g.) was related to pre-mating maternal serum total thyroxine $\left(\mathrm{TT}_{4}\right)$ levels; permanent fetal growth retardation occurred in severely $\left(\mathrm{TX}_{\mathrm{s}}\right.$; pre-mating maternal serum $\mathrm{TT}_{4} \leq 16.19 \mathrm{nM}$ ) - but not in moderately $\left(\mathrm{TX}_{\mathrm{m}}\right)$ - hypothyroid dams. In $\mathrm{TX}_{\mathrm{s}}$ dams, glycogen
\end{abstract}

concentration was elevated in maternal liver and in the fetal side of the placenta at 16 and 19 d.g., and in the maternal side of the placenta at 19 and 21 d.g., despite maternal euglycemia. In contrast, fetal liver glycogen concentration was deficient in $\mathrm{TX}_{\mathrm{m}}$ dams at $19 \mathrm{~d}$.g. and in $\mathrm{TX}_{\mathrm{s}}$ dams at 19 and 21 d.g., and fetal hypoglycemia occurred in $\mathrm{TX}_{\mathrm{s}}$ dams at $21 \mathrm{~d}$ d.g. Multiple regression analyses indicate that these fetal deficits are strongly associated with the retardation in fetal growth, while the elevated maternal liver and placental glycogen concentrations have no impact on fetal growth near term. The mechanisms by which severe maternal hypothyroidism permanently retards rat fetal growth remain to be determined.

Journal of Endocrinology (2003) 176, 247-255

\section{Introduction}

Maternal hypothyroidism influences feto-placental growth in rats, though the outcome depends on the timing of thyroidectomy in relation to conception and the degree of hypothyroidism. Thyroidectomy of rats before pregnancy has no effect on placental growth, but retards fetal growth, either transiently in moderately hypothyroid dams (Pickard et al. 1999) or permanently in severely hypothyroid dams (Morreale de Escobar et al. 1985, Leonard et al. 1999). In contrast, induction of moderate or severe maternal hypothyroidism soon after conception permanently retards placental and fetal growth (Porterfield et al. 1975, Bonet \& Herrera 1988, Hendrich \& Porterfield 1992).

The mechanisms by which maternal thyroid status regulates fetal development are poorly understood. Direct action is possible, since materno-fetal thyroxine $\left(T_{4}\right)$ transfer occurs in rat pregnancy, and fetal tissues express $5^{\prime}$-deiodinases and nuclear 3,5,3'-tri-iodothyronine $\left(\mathrm{T}_{3}\right)$ receptors (TR) (Porterfield \& Hendrich 1993, Pickard et al. 1997, Morreale de Escobar et al. 2000). The placenta also accumulates and metabolizes maternal $\mathrm{T}_{4}$ and $\mathrm{T}_{3}$ (Calvo et al. 1992) and expresses TR (Leonard et al. 2001); thus maternal thyroid hormone may regulate fetal development via effects on the placenta. Finally, other indirect mechanisms involving maternal tissues (Bonet \& Herrera 1988, Hendrich \& Porterfield 1992) may be influential.

In dams made hypothyroid soon after conception, maternal metabolic compromise occurs (Bonet \& Herrera 1988) which, together with reduced placental size, may restrict the provision of nutrients to the fetus, resulting in permanent fetal growth retardation. Whether dams made hypothyroid before pregnancy also suffer metabolic compromise is unknown. Although placental size is normal in the latter model, moderate maternal hypothyroidism compromises placental expression of glucose transporter (GLUT) protein isoforms (Pickard et al. 1999). Furthermore, $\mathrm{T}_{3}$ administration to rat dams during late pregnancy depletes placental glycogen stores (Shafrir et al. 
1994). Thus maternal thyroid status may regulate placental glycogen homeostasis and glucose transport and hence the supply of maternal glucose to the fetus. Since glucose serves as the primary fetal growth substrate, and the rat fetus is incapable of gluconeogenesis (Jones \& Rolph 1985, Girard et al. 1992), we postulate that in dams made hypothyroid before pregnancy, permanent fetal growth retardation occurs as a consequence of disturbances in maternal and placental glycogen storage and hence glucose supply to the fetus (i.e. maternal and/or placental glucose metabolic compromise).

To test this hypothesis, we first examined the relationship between pre-mating maternal thyroid status and fetal body weight in partially thyroidectomized (TX group) and euthyroid rat dam pregnancies, and exploited the relationship near term to assign TX dam pregnancies at all stages of gestation to severely hypothyroid $\left(\mathrm{TX}_{\mathrm{s}}\right.$; permanently growth-retarded) and more moderately hypothyroid $\left(\mathrm{TX}_{\mathrm{m}}\right)$ groups. We then examined whether moderate and severe maternal hypothyroidism influences placental, maternal liver and fetal liver glycogen stores, as well as maternal and fetal glycemic status. Finally, we addressed whether compromise in maternal liver and placental glycogen concentrations contributes to permanent fetal growth retardation in TX dams.

\section{Materials and Methods}

\section{Materials}

All enzymes and fine chemicals were from Sigma-Aldrich Company Limited (Gillingham, Dorset, UK). The total $\mathrm{T}_{4}$ $\left(\mathrm{TT}_{4}\right)$ RIA kit was from NETRIA (London, UK) and the total $\mathrm{T}_{3}\left(\mathrm{TT}_{3}\right)$ RIA kit from BM Browne (UK) Limited (Reading, Berks, UK).

\section{Animal model}

Sprague-Dawley female rats (proven breeders) were partially thyroidectomized by surgical removal of the lower one-half to two-thirds of each lobe, sparing the parathyroids, and allowed to recover for at least 2 weeks. Circulating $\mathrm{TT}_{4}$ levels were determined and the animals mated overnight with normal males; the morning of appearance of a vaginal plug was designated day 0 of pregnancy. Normal ( $\mathrm{N}$ group) females served as the control group. Animals were maintained in the local animal house facilities at $22{ }^{\circ} \mathrm{C}$ on a cycle of $14 \mathrm{~h}$ light : $10 \mathrm{~h}$ darkness, and allowed free access to a standard small laboratory animal diet and water. The water of the TX group was supplemented with $0 \cdot 1 \%(\mathrm{w} / \mathrm{v})$ calcium lactate throughout.

Animals were stunned and killed by cervical dislocation at 16, 19 and 21 days gestation (d.g.); fetal thyroid hormone secretion occurs from $17.5 \mathrm{~d}$.g. (Morreale de
Escobar et al. 1985) and parturition at 22 d.g. Maternal blood was collected by cardiac puncture and the uterine horns were removed to ice. Fetuses and placentae were isolated and weighed, then fetal tissues were dissected and weighed. Tissue pools (from $\geq$ three fetuses) were immediately frozen on dry ice and stored at $-20{ }^{\circ} \mathrm{C}$ until assay.

Samples were collected from 17 different batches of animals. In the light of initial findings, the tissue collection protocol was modified for the latter seven batches to include maternal liver (left lateral lobe), amniotic fluid and fetal blood; placental discs were also separated into maternal (junctional zone) and fetal (labyrinth) sides.

All experimental procedures complied with the Animal (Scientific Procedures) Act 1986 of the United Kingdom.

\section{Glycogen and glucose determination}

Liver and placental samples were deproteinized by homogenization with 5 volumes ice-cold $0.6 \mathrm{M}$ perchloric acid, and glycogen was determined by a standard procedure, employing fungal glucoamylase for hydrolysis (Keppler \& Decker 1984). A rabbit liver glycogen preparation $(0.45 \mathrm{M})$ was included with each batch of samples to verify complete hydrolysis.

Glucose was determined in neutralized tissue homogenates and hydrolysates, sera and amniotic fluid using a standard spectrophotometric procedure with hexokinase and glucose 6-phosphate dehydrogenase (Keppler \& Decker 1984); glucose standards (10-250 nmol) were included in each assay. Glycogen concentrations, expressed as $\mu \mathrm{mol}$ glucose/g tissue wet weight, were corrected for endogenous glucose (Keppler \& Decker 1984).

\section{Thyroid hormone determination}

Levels of $\mathrm{TT}_{4}$ and $\mathrm{TT}_{3}$ were determined in maternal serum by RIA. Inter- and intra-assay coefficients of variance were, respectively, $5 \cdot 8$ and $4.5 \%$ for $\mathrm{TT}_{4}$, and $5 \cdot 7$ and $3 \cdot 3 \%$ for $\mathrm{TT}_{3}$.

\section{Statistical analysis}

Data from $\mathrm{N}$ and TX dam pregnancies were compared by one-way ANOVA; Fisher's protected least significance differences (PLSD) were determined for post hoc analysis. Homogeneity of variance for all groups was assessed using Bartlett's test for samples of unequal size and, where necessary, a square root or $\log _{\mathrm{e}}$ transformation was applied before analysis. For simple and multiple regression analyses, linearity of the data was determined by a runs test. Statistical analyses were performed using Statview 1.03 (Abacus Concepts, Inc., Berkeley, CA, USA) and 


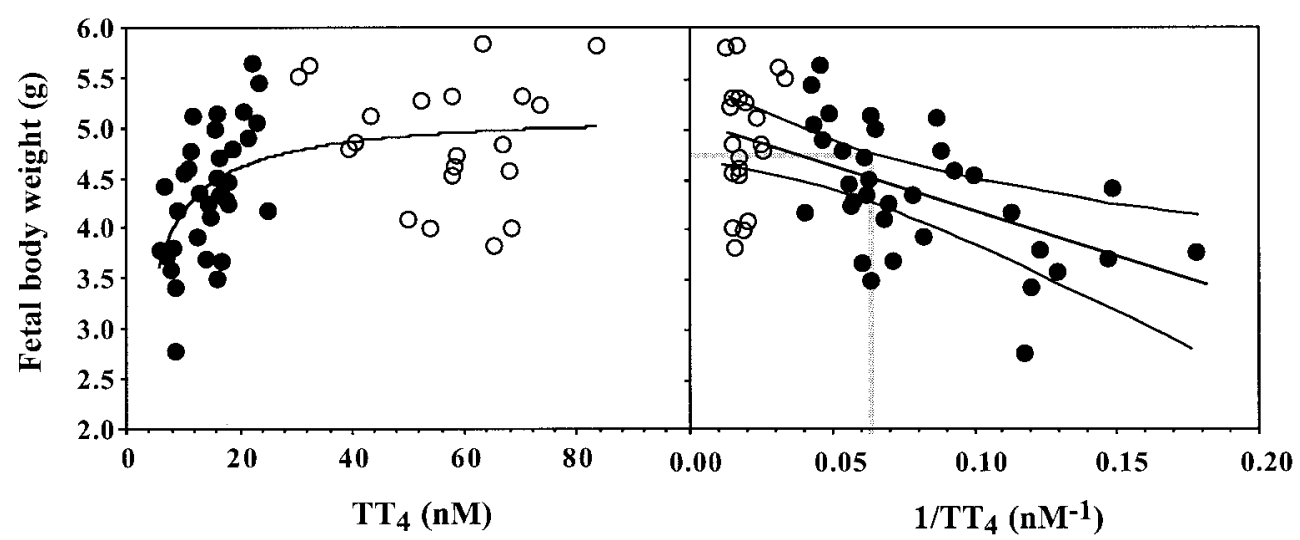

Figure 1 Relationship between fetal body weight near term and pre-mating maternal serum $\Pi_{4}$ level. Data derived from $\mathrm{N}(O ; n=20)$ and $\operatorname{TX}(\mathbf{O} ; n=34)$ dam pregnancies at $21 \mathrm{~d}$.g. were consistent with a hyperbolic relationship (left panel). Regression of fetal body weight on the reciprocal of pre-mating maternal serum $T_{4}$ (right panel) yielded a linear relationship $(y=-9 \cdot 042 x+5 \cdot 088 ; r=-0 \cdot 547 ; P<0 \cdot 001)$. The 99\% confidence interval of the intercept at $5.09 \mathrm{~g}$ was calculated, and the grey line indicates extrapolation of the lower limit of $4.73 \mathrm{~g}$ across to the upper $99 \%$ confidence limit of the regression line. This corresponds to a pre-mating maternal serum $\Pi_{4}$ level of $16 \cdot 19 \mathrm{nM}$, at or below which permanent fetal growth retardation is considered to occur.

GraphPad Prism 2.0c (GraphPad Software, Inc., San Diego, CA, USA); statistical significance was defined as $P<0 \cdot 05$. Results are expressed as means \pm S.E.M.

\section{Results}

Relationship between fetal body weight and pre-mating maternal serum $\mathrm{TT}_{4}$ levels

Previous studies with the TX dam model have shown that in moderate maternal hypothyroidism, fetal body weight is reduced at 16 d.g. but normal at 21 d.g. (Pickard et al. 1999), whereas in severe maternal hypothyroidism, late fetal growth is also retarded (Leonard et al. 1999). Indeed in the present study, fetal body weights at 16-21 d.g. were found to vary with pre-mating maternal serum $\mathrm{TT}_{4}$ levels, in a manner consistent with a hyperbolic relationship at each age (Fig. 1 left panel and data not shown). Consequently, fetal body weight exhibited an inverse linear relationship with the reciprocal of pre-mating maternal serum $\mathrm{TT}_{4}$ at 16 d.g. $(r=-0.526 ; P<0 \cdot 001$; $n=61), 19$ d.g. $(r=-0 \cdot 339 ; P=0 \cdot 011 ; n=55)$ and $21 \mathrm{~d} . \mathrm{g}$. (Fig. 1 right panel). The relationship at 21 d.g. allowed statistical determination of the pre-mating maternal serum $\mathrm{TT}_{4}$ level which would be expected to give rise to permanently growth-retarded fetuses. The $99 \%$ confidence interval of the $\gamma$-axis intercept in the reciprocal plot was calculated (Altman \& Gardner 1989), and the lower limit extrapolated to the upper $99 \%$ confidence limit of the regression line, corresponding to a pre-mating $\mathrm{TT}_{4}$ level of $16 \cdot 19 \mathrm{nM}$ (Fig. 1 right panel). This value was used to assign TX dams at all stages of gestation to moderately $\left(\mathrm{TX}_{\mathrm{m}}\right.$ dams; pre-mating $\left.\mathrm{TT}_{4} \leq 16 \cdot 19 \mathrm{nM}\right)$ and severely
( $\mathrm{TX}_{\mathrm{s}}$ dams; pre-mating $\mathrm{TT}_{4}=16 \cdot 19 \mathrm{nM}$ ) hypothyroid groups, in order to better explore how severe maternal hypothyroidism retards late fetal growth.

\section{Maternal thyroid status}

Pre-mating maternal serum $\mathrm{TT}_{4}$ levels were reduced in $\mathrm{TX}_{\mathrm{m}}$ and $\mathrm{TX}_{\mathrm{s}}$ dams compared with $\mathrm{N}$ dams, and in $\mathrm{TX}_{\mathrm{s}}$ dams compared with $\mathrm{TX}_{\mathrm{m}}$ dams (Table 1), as expected. Within each treatment group, pre-mating $\mathrm{TT}_{4}$ levels were similar irrespective of the stage of gestation studied.

Maternal serum $\mathrm{TT}_{4}$ levels were reduced in both $\mathrm{TX}$ dam groups relative to $\mathrm{N}$ dams at all ages during pregnancy, and in $\mathrm{TX}_{\mathrm{s}}$ dams relative to $\mathrm{TX}_{\mathrm{m}}$ dams at 16 and 19 d.g. (Table 1). Maternal serum $\mathrm{TT}_{4}$ levels at each stage

Table 1 Serum thyroid hormone levels in $N, T_{m}$ and $T_{s}$ dams before mating and during pregnancy

\begin{tabular}{|c|c|c|c|c|}
\hline & \multirow[b]{2}{*}{ Dam } & \multirow{2}{*}{$\frac{\text { Pre-mating }}{\pi_{4}(n M)}$} & \multicolumn{2}{|l|}{ Pregnancy } \\
\hline & & & $\pi_{4}(\mathrm{nM})$ & $\pi_{3}(\mathrm{nM})$ \\
\hline 16 d.g. & $\begin{array}{l}\mathrm{N} \\
\mathrm{TX}_{\mathrm{m}} \\
\mathrm{TX}_{\mathrm{s}}\end{array}$ & $\begin{array}{l}53 \cdot 5 \pm 2 \cdot 1 \\
19 \cdot 9 \pm 0 \cdot 9^{\mathrm{c}} \\
11 \cdot 4 \pm 0 \cdot 5^{\mathrm{c}, \mathrm{f}}\end{array}$ & $\begin{array}{l}40 \cdot 9 \pm 1 \cdot 9 \\
17 \cdot 8 \pm 1 \cdot 5^{\mathrm{c}} \\
12 \cdot 2 \pm 0 \cdot 6^{\mathrm{c}, e}\end{array}$ & $\begin{array}{l}1 \cdot 05 \pm 0 \cdot 12 \\
0 \cdot 57 \pm 0 \cdot 10^{\mathrm{C}} \\
0 \cdot 41 \pm 0 \cdot 07^{\mathrm{C}}\end{array}$ \\
\hline 19 d.g. & $\begin{array}{l}\mathrm{N} \\
\mathrm{TX}_{\mathrm{m}} \\
\mathrm{TX}_{\mathrm{s}}\end{array}$ & $\begin{array}{l}55 \cdot 9 \pm 3 \cdot 4 \\
20 \cdot 4 \pm 0 \cdot 9^{c} \\
10 \cdot 4 \pm 0 \cdot 5^{c, f}\end{array}$ & $\begin{aligned} 27 \cdot 8 & \pm 1 \cdot 2 \\
13 \cdot 2 & \pm 1 \cdot 2^{\mathrm{c}} \\
9 \cdot 9 & \pm 1 \cdot 0^{\mathrm{c}, \mathrm{d}}\end{aligned}$ & $\begin{array}{l}1 \cdot 03 \pm 0 \cdot 12 \\
0 \cdot 59 \pm 0 \cdot 08^{a} \\
0 \cdot 34 \pm 0 \cdot 06^{c}\end{array}$ \\
\hline 21 d.g. & $\begin{array}{l}\mathrm{N} \\
\mathrm{TX}_{\mathrm{m}} \\
\mathrm{TX}_{\mathrm{s}}\end{array}$ & $\begin{array}{l}56 \cdot 5 \pm 3 \cdot 1 \\
19 \cdot 7 \pm 0 \cdot 8^{\mathrm{c}} \\
11 \cdot 2 \pm 0 \cdot 7^{\mathrm{c}, \mathrm{f}}\end{array}$ & $\begin{array}{r}19 \cdot 8 \pm 1 \cdot 6 \\
10 \cdot 5 \pm 1 \cdot 3^{\mathrm{C}} \\
8 \cdot 3 \pm 1 \cdot 0^{\mathrm{C}}\end{array}$ & $\begin{array}{l}0.69 \pm 0.09 \\
0.52 \pm 0.14 \\
0.45 \pm 0.15^{b}\end{array}$ \\
\hline
\end{tabular}

${ }^{\mathrm{a}} P<0.02,{ }^{\mathrm{b}} P<0.01$ and ${ }^{\mathrm{C}} P<0.001 \mathrm{TX}_{\mathrm{m}}$ or $\mathrm{TX}_{\mathrm{s}} \mathrm{vs} \mathrm{N}$ dam; ${ }^{\mathrm{d}} P<0.05,{ }^{\mathrm{e}} P<0.005$ and ${ }^{\mathrm{f}} P<0.001 \mathrm{TX}_{\mathrm{s}}$ vs $\mathrm{TX}_{\mathrm{m}}$ dam; $n \geq 13$ different pregnancies. 
Table 2 Litter size and feto-placental growth in $\mathrm{N}, \mathrm{TX}_{\mathrm{m}}$ and $\mathrm{TX}_{\mathrm{s}}$ dam pregnancies

Tissue weight $(\mathrm{mg})$

\begin{tabular}{|c|c|c|c|c|c|c|c|c|}
\hline \multirow{3}{*}{\multicolumn{2}{|c|}{ Dam }} & \multirow[b]{3}{*}{ Litter size } & \multirow[b]{3}{*}{ Fetal body } & \multirow[b]{3}{*}{ Fetal brain } & \multirow[b]{3}{*}{ Fetal liver } & \multirow{2}{*}{\multicolumn{3}{|c|}{ Placenta }} \\
\hline & & & & & & & & \\
\hline & & & & & & Whole & Maternal & Fetal \\
\hline \multirow{3}{*}{16 d.g. } & $\mathrm{N}$ & $16 \cdot 7 \pm 0 \cdot 6$ & $489 \pm 7$ & $53 \cdot 4 \pm 0 \cdot 8$ & $28 \cdot 6 \pm 0 \cdot 8$ & $326 \pm 9$ & $153 \pm 5$ & $147 \pm 4$ \\
\hline & $\mathrm{TX}_{\mathrm{m}}$ & $12 \cdot 6 \pm 1 \cdot 0^{\mathrm{d}}$ & $449 \pm 8^{b}$ & $49 \cdot 5 \pm 1 \cdot 2^{\mathrm{a}}$ & $27 \cdot 1 \pm 1 \cdot 7$ & $336 \pm 14$ & $168 \pm 7$ & $146 \pm 8$ \\
\hline & $\mathrm{TX}_{\mathrm{s}}^{\mathrm{m}}$ & $12 \cdot 4 \pm 0 \cdot 7^{d}$ & $439 \pm 6^{d}$ & $48 \cdot 7 \pm 1 \cdot 2^{c}$ & $24 \cdot 4 \pm 0 \cdot 9^{d}$ & $334 \pm 14$ & $153 \pm 10$ & $136 \pm 8$ \\
\hline \multirow[t]{3}{*}{19 d.g. } & $\mathrm{N}$ & $15 \cdot 9 \pm 0 \cdot 8$ & $2240 \pm 32$ & $130 \cdot 0 \pm 1 \cdot 4$ & $161 \cdot 5 \pm 3 \cdot 1$ & $526 \pm 18$ & $164 \pm 10$ & $292 \pm 9$ \\
\hline & $\mathrm{TX}_{\mathrm{m}}$ & $12 \cdot 6 \pm 0 \cdot 6^{\mathrm{b}}$ & $2143 \pm 41$ & $129 \cdot 7 \pm 2 \cdot 8$ & $155 \cdot 1 \pm 6 \cdot 0$ & $519 \pm 19$ & $153 \pm 10$ & $296 \pm 13$ \\
\hline & $\mathrm{TX}_{\mathrm{s}}$ & $11 \cdot 1 \pm 0 \cdot 6^{\mathrm{d}}$ & $2034 \pm 39^{d}$ & $125 \cdot 7 \pm 1 \cdot 1$ & $144 \cdot 4 \pm 3 \cdot 1^{a}$ & $546 \pm 11$ & $167 \pm 8$ & $297 \pm 15$ \\
\hline \multirow[t]{3}{*}{21 d.g. } & $N$ & $16 \cdot 8 \pm 0 \cdot 8$ & $4936 \pm 110$ & $191 \cdot 0 \pm 2 \cdot 3$ & $290 \cdot 5 \pm 8 \cdot 8$ & $570 \pm 22$ & $152 \pm 11$ & $340 \pm 12$ \\
\hline & $\mathrm{TX}_{\mathrm{m}}$ & $12 \cdot 3 \pm 1 \cdot 0^{\mathrm{d}}$ & $4697 \pm 154$ & $185 \cdot 5 \pm 3 \cdot 2$ & $243 \cdot 0 \pm 11 \cdot 3^{c}$ & $589 \pm 23$ & $147 \pm 18$ & $304 \pm 8$ \\
\hline & $\mathrm{TX}_{\mathrm{s}}^{\mathrm{m}}$ & $10 \cdot 1 \pm 0 \cdot 6^{d}$ & $4163 \pm 134^{\mathrm{d}, \#}$ & $179 \cdot 4 \pm 2 \cdot 7^{d}$ & $220 \cdot 5 \pm 8 \cdot 5^{d}$ & $578 \pm 15$ & $149 \pm 12$ & $318 \pm 9$ \\
\hline
\end{tabular}

${ }^{a} P<0.02,{ }^{b} P<0.005,{ }^{c} P<0.002$ and ${ }^{d} P<0.001 \mathrm{TX}_{\mathrm{m}}$ or $\mathrm{TX}_{\mathrm{s}} \mathrm{vs} \mathrm{N}$ dam; ${ }^{\#} P<0.001 \mathrm{TX}_{\mathrm{s}} \mathrm{vs} \mathrm{TX}_{\mathrm{m}}$ dam; $n \geq 6$ different pregnancies for weights of maternal and fetal placenta and $\geq 12$ for all other parameters.

of pregnancy were highly correlated with pre-mating serum $\mathrm{TT}_{4}$ levels $(r=0 \cdot 658 ; P<0 \cdot 001 ; n=53)$.

Compared with $\mathrm{N}$ dams, maternal serum $\mathrm{TT}_{3}$ levels were lower in $\mathrm{TX}_{\mathrm{m}}$ and $\mathrm{TX}_{\mathrm{s}}$ dams at 16 and 19 d.g. (Table 1). Levels declined between 19 and 21 d.g. in $N$ dams $(P<0 \cdot 05)$, but remained stable in $\mathrm{TX}_{\mathrm{m}}$ and $\mathrm{TX}_{\mathrm{s}}$ dams, so that at 21 d.g., only $\mathrm{TX}_{\mathrm{s}}$ dams showed depressed serum $\mathrm{TT}_{3}$ levels relative to $\mathrm{N}$ dams.

\section{Litter size and feto-placental growth}

The number of fetuses carried by $\mathrm{TX}_{\mathrm{m}}$ and $\mathrm{TX}_{\mathrm{s}}$ dams was reduced at all ages relative to $\mathrm{N}$ dams (Table 2). Litter size in $\mathrm{TX}_{\mathrm{s}}$ dams was lower $(P<0 \cdot 05)$ at $21 \mathrm{~d}$.g. than at 16 d.g., and regression analysis confirmed a linear relationship $(r=-0.304 ; P=0.014 ; n=65)$ between litter size and gestational age over the period $16-21 \mathrm{~d} . \mathrm{g}$. in $\mathrm{TX}_{\mathrm{s}}$ dams alone.

Fetal body weight at 21 d.g. was reduced ( $84 \%$ control value) in $\mathrm{TX}_{\mathrm{s}}$ dams only (Table 2 ), as expected, and less marked fetal body weight deficits (c. 90\% control value) were also seen in $\mathrm{TX}_{\mathrm{s}}$ dams at 16 and 19 d.g. Fetuses from $\mathrm{TX}_{\mathrm{m}}$ dams, in contrast, exhibited reduced fetal body weight at 16 d.g. only (Table 2). Fetal brain weight was reduced by a similar extent to fetal body weight in $\mathrm{TX}_{\mathrm{m}}$ and $\mathrm{TX}_{\mathrm{s}}$ dams at 16 d.g., but normalized in both groups by 19 d.g. (Table 2). It was however again reduced in $\mathrm{TX}_{\mathrm{s}}$ dams at 21 d.g. (Table 2). Fetal brain:body weight ratios were elevated in $\mathrm{TX}_{\mathrm{s}}$ dams at 19 d.g. $(0 \cdot 062 \pm 0 \cdot 001$ vs $0 \cdot 058 \pm 0 \cdot 001$ for controls; $P<0 \cdot 05 ; n=22)$ and at $21 \mathrm{~d} . \mathrm{g}$. $(0.044 \pm 0.001$ vs $0.039 \pm 0.001$ for controls; $P<0.05$; $n=20$ ). Fetal liver weights were deficient in $\mathrm{TX}_{\mathrm{s}}$ dams at all ages and in $\mathrm{TX}_{\mathrm{m}}$ dams at 21 d.g. (Table 2). Fetal liver:body weight ratios were reduced at $21 \mathrm{~d}$.g. in $\mathrm{TX}_{\mathrm{m}}$ dams $(0 \cdot 052 \pm 0 \cdot 001 ; P<0 \cdot 05 ; n=12)$ and $\mathrm{TX}_{\mathrm{s}}$ dams $(0 \cdot 052 \pm 0 \cdot 002 ; P<0 \cdot 05 ; n=20)$ compared with $\mathrm{N}$ dams $(0 \cdot 058 \pm 0 \cdot 002 ; n=23)$.
In $\mathrm{N}$ dams, the weight of the maternal side of the placenta remained constant over the period studied, whereas that of the fetal side more than doubled (Table 2), as expected (Davies \& Glasser 1968), so that near term the fetal side accounted for two-thirds of total placental mass, in keeping with published data (Ne'eman et al. 1987). The weight of the placenta, either whole or after separation into maternal and fetal sides, was normal in all TX dams (Table 2).

\section{Tissue glycogen levels}

For all tissues from euthyroid pregnancies, glycogen concentrations and their ontogeny agreed with published data (Gruppuso \& Brautigan 1989, Shafrir \& Barash 1991).

Fetal liver glycogen concentration and content were low in $\mathrm{N}$ dams at $16 \mathrm{~d}$.g., then increased markedly as gestation progressed (Table 3). Relative to $\mathrm{N}$ dams, fetal liver glycogen levels were lower in $\mathrm{TX}_{\mathrm{m}}$ and $\mathrm{TX}_{\mathrm{s}}$ dams at 19 d.g. and in $\mathrm{TX}_{\mathrm{s}}$ dams at 21 d.g. Furthermore, upon combining data from all pregnancies, fetal liver glycogen concentration was inversely related to the reciprocal of pre-mating maternal serum $\mathrm{TT}_{4}$ at both 19 d.g. $(r=$ $-0.469 ; \quad P=0.014 ; \quad n=27)$ and 21 d.g. $\quad(r=-0 \cdot 522$; $P=0 \cdot 001 ; n=31)$. However, fetal liver glycogen concentration was directly related to fetal body weight at $19 \mathrm{~d}$.g. $(r=0.656 ; P<0.001)$ and at $21 \mathrm{~d} . \mathrm{g} .(r=0.743 ; P<0 \cdot 001)$, so that depressed fetal liver glycogen stores in TX dams may occur secondary to retarded fetal growth. Indeed multiple regression analysis of these data revealed that fetal liver glycogen concentration was significantly related to fetal body weight at 19 d.g. $(P=0.001)$ and at 21 d.g. $(P<0 \cdot 001)$, but not to the reciprocal of pre-mating maternal serum $\mathrm{TT}_{4}$ (albeit $P=0.087$ at 19 d.g.).

Maternal liver glycogen concentration, in contrast, declined between 16 and 21 d.g. in $\mathrm{N}$ dams (Table 3), and was elevated in $\mathrm{TX}_{\mathrm{s}}$ dams at 16 and 19 d.g. relative to 
Table 3 Maternal and fetal liver glycogen levels in $\mathrm{N}, \mathrm{TX}_{\mathrm{m}}$ and $\mathrm{TX}_{\mathrm{s}}$ dam pregnancies

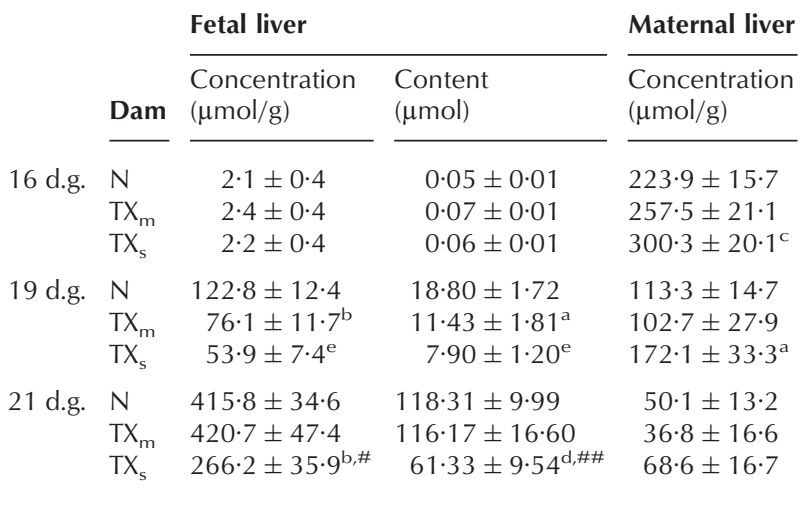

${ }^{a} P<0.05,{ }^{b} P<0.02,{ }^{c} P<0.01,{ }^{d} P<0.002$ and ${ }^{e} P<0.001 \mathrm{TX}_{\mathrm{m}}$ or $\mathrm{TX}_{\mathrm{s}}$ vs $\mathrm{N}$ dam; ${ }^{\#} P<0.05$ and ${ }^{\# \#} P<0.01 \mathrm{TX}_{\mathrm{s}}$ vs $\mathrm{TX}_{\mathrm{m}}$ dam; $n \geq 8$ different pregnancies for fetal liver, and $\geq 4$ for maternal liver.

controls. Regression of maternal liver glycogen concentration on the reciprocal of pre-mating maternal serum $\mathrm{TT}_{4}$ yielded significant linear relationships at $16 \mathrm{~d}$.g. $(r=0.455 ; \quad P=0.026 ; n=24)$ and at 19 d.g. $(r=0.533$; $P=0.011 ; n=22)$. However, reductions in litter size and fetal body weight may have contributed to elevated maternal liver glycogen levels in $\mathrm{TX}_{\mathrm{s}}$ dams by placing less demand on maternal glucose reserves. In this regard, maternal liver glycogen concentration in N, $\mathrm{TX}_{\mathrm{m}}$ and $\mathrm{TX}_{\mathrm{s}}$ dams combined was negatively correlated with litter size at 16 d.g. $(r=-0.459 ; P=0 \cdot 02 ; n=24)$ and at 19 d.g. $(r=$ $-0.568 ; P=0.006 ; n=22)$, but was unrelated to fetal body weight. Multiple regression analysis of combined 16 and 19 d.g. data was therefore performed; this yielded a significant relationship $(R=0.813 ; \quad P<0.001 ; n=46)$, maternal liver glycogen concentration being directly related to the reciprocal of pre-mating maternal serum $\mathrm{TT}_{4}(P=0.039)$ and inversely related to the number of fetuses $(P=0.018)$ and days gestation $(P<0.001)$. Thus, elevated maternal liver glycogen concentration in $\mathrm{TX}_{\mathrm{s}}$ dams at 16 and 19 d.g. may occur due to reductions in litter size and circulating maternal thyroid hormone levels per se.

The placental glycogen concentration also fell between 16 and 21 d.g. in $\mathrm{N}$ dams (Fig. 2). This decline was more pronounced between 16 and 19 d.g. in the maternal side than the fetal side, though glycogen concentration was higher in the former side at all stages, as expected (Ne'eman et al. 1987). Relative to $\mathrm{N}$ dams, glycogen concentration in total and maternal placenta from $\mathrm{TX}_{\mathrm{s}}$ dams was elevated to a similar extent at $19 \mathrm{~d}$.g. and at 21 d.g., whereas it was elevated in fetal placenta from $\mathrm{TX}_{\mathrm{s}}$ dams at 16 and 19 d.g. (Fig. 2). Glycogen content showed a similar ontogeny to glycogen concentration in normal total and maternal placenta, and was similarly influenced by maternal thyroidectomy (Fig. 2). In contrast, glycogen content in the fetal side increased $(P<0.05)$ slightly between 16 and 19 d.g. in $\mathrm{N}$ dams, as the mass of this tissue doubled (Table 2); treatment-associated changes were limited to an elevation in $\mathrm{TX}_{\mathrm{s}}$ dams at $19 \mathrm{~d}$.g. (Fig. 2).

Regression of the maternal placental glycogen concentration at 19 or 21 d.g. on the reciprocal of the pre-mating maternal serum $\mathrm{TT}_{4}$ level revealed significant relationships (Fig. 3) of comparable slope but different $(P<0.001)$ elevation. The fetal placental glycogen concentration at 19 d.g. only was related to the reciprocal of the pre-mating maternal serum $\mathrm{TT}_{4}$ level, albeit the data at $16 \mathrm{~d}$.g. were highly scattered (Fig. 3). Since fetal size was reduced in TX dams, fetal demands on placental metabolic stores may be reduced, and this may in part explain the elevated maternal and fetal placental glycogen concentrations. However only the maternal placental glycogen concentration at 21 d.g. was related to fetal body weight $(r=-0.518 ; \quad P=0.006 ; n=27)$. Furthermore, multiple regression analysis of these data against the reciprocal of pre-mating maternal serum $\mathrm{TT}_{4}$ and fetal body weight yielded a significant relationship $(R=0.598 ; P=0.005$; $n=27$ ), but only the relationship between the maternal placental glycogen concentration and the reciprocal of pre-mating maternal serum $\mathrm{TT}_{4}$ tended towards statistical significance $(P=0 \cdot 080)$. Reduced fetal size is therefore unlikely to account for elevated placental glycogen stores in $\mathrm{TX}_{\mathrm{s}}$ dams.

\section{Serum and amniotic fluid glucose concentrations}

The maternal serum glucose concentration was normal in TX dams at all stages (Table 4). Fetal serum glucose at 16 and $21 \mathrm{~d}$.g. displayed hyperbolic relationships with premating maternal serum $\mathrm{TT}_{4}$ (Fig. 4), but levels were only reduced in $\mathrm{TX}_{\mathrm{s}}$ dams at $21 \mathrm{~d} . \mathrm{g}$. (Table 4). The amniotic fluid glucose concentration at $16 \mathrm{~d}$.g. also displayed a hyperbolic relationship with pre-mating maternal serum $\mathrm{TT}_{4}$ (Fig. 4) and was reduced in $\mathrm{TX}_{\mathrm{m}}$ and $\mathrm{TX}_{\mathrm{s}}$ dams at this stage only (Table 4).

At 16 d.g., amniotic fluid glucose was related to fetal body weight $(r=0.518 ; P=0.007 ; n=26)$, as was the case at 21 d.g. for fetal serum glucose $(r=0.599 ; P<0.001$; $n=37)$. Upon multiple regression analysis, fetal serum glucose at 21 d.g. $(R=0.599 ; P<0 \cdot 001)$ was related to fetal body weight $(P=0 \cdot 001)$ but no longer to the reciprocal of pre-mating maternal serum $\mathrm{TT}_{4}$, whereas amniotic fluid glucose at 16 d.g. $(R=0.606 ; P=0.005)$ failed to show a significant relationship with either fetal body weight or the reciprocal of pre-mating maternal serum $\mathrm{TT}_{4}$ (albeit $P=0.077$ and 0.071 respectively). Thus, in $\mathrm{TX}_{\mathrm{s}}$ dams near term at least, the apparent fetal hypoglycemia is likely to arise secondary to fetal growth retardation, since the fetal serum glucose concentration appears normal for fetal body 

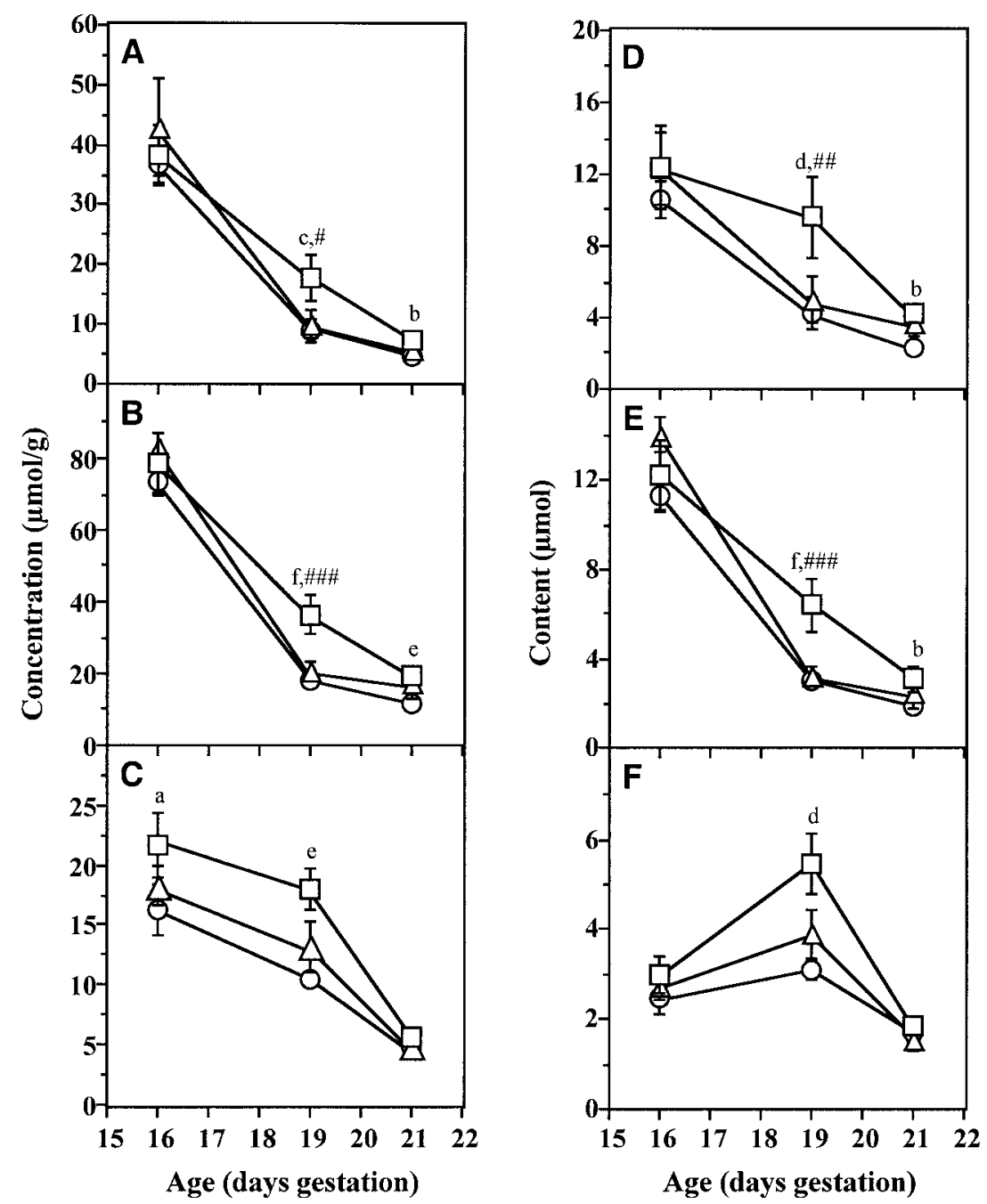

Figure 2 Placental glycogen levels in $N, \mathrm{TX}_{\mathrm{m}}$ and $\mathrm{TX}_{\mathrm{s}}$ dams. Glycogen concentration $(\mathrm{A}-\mathrm{C}$ ) and content (D-F) are shown for total placenta $(A$ and $D)$, the maternal side (B and $E$ ) and the fetal side $\left(\mathrm{C}\right.$ and $\mathrm{F}$ ) from $\mathrm{N}(O), \mathrm{TX}_{\mathrm{m}}(\triangle)$ and $\mathrm{TX}_{\mathrm{s}}(\square)$ dams. Results are expressed as means \pm S.E.M. ${ }^{\mathrm{a}} P<0.05,{ }^{\mathrm{b}} P<0.02,{ }^{\mathrm{c}} P<0.01,{ }^{\mathrm{d}} P<0.005,{ }^{\mathrm{e}} P<0.002$ and ${ }^{\mathrm{f}} P<0.001 \mathrm{TX}_{\mathrm{s}}$ vs $\mathrm{N}$ dam; ${ }^{\#} P<0.05,{ }^{\# \#} P<0.02$ and ${ }^{\# \# \#} P<0.01 \mathrm{TX}_{\mathrm{s}} \vee \mathrm{s} \mathrm{TX}$ m dam; $n \geq 4$ pregnancies for total placenta and $\geq$ a further six pregnancies for maternal/fetal placenta.

weight, albeit both parameters are depressed in $\mathrm{TX}_{\mathrm{s}}$ dams relative to $\mathrm{N}$ dams.

Fetal growth retardation near term is unrelated to maternal and placental glucose metabolic compromise

The onset of fetal thyroid activity rapidly normalizes fetal tissue thyroid hormone pools in overtly hypothyroid rat dams (Ruiz de Ona et al. 1991), so that persisting fetal hypothyroidism cannot explain the pronounced fetal body weight deficits in $\mathrm{TX}_{\mathrm{s}}$ dams near term. In this study, the observation in TX dams that fetal serum glucose levels appear normal for fetal body weight, and that maternal serum glucose concentrations were normal, further suggests that neither placental nor maternal glucose metabolic compromise contribute to fetal growth retardation in hypothyroid pregnancies near term. To test this proposal, a subset $(n=17)$ of $\mathrm{N}$ and TX dam pregnancies at $21 \mathrm{~d}$.g. was selected for which fetal body weight, litter size, pre-mating maternal serum $\mathrm{TT}_{4}$, maternal serum glucose, maternal hepatic glycogen and maternal placental glycogen concentrations were all characterized. Multiple regression analysis was performed using a stepwise procedure with fetal body weight as the dependent variable and all other parameters (the reciprocal of pre-mating maternal serum $\mathrm{TT}_{4}$ was used for this analysis) as predictor variables. 


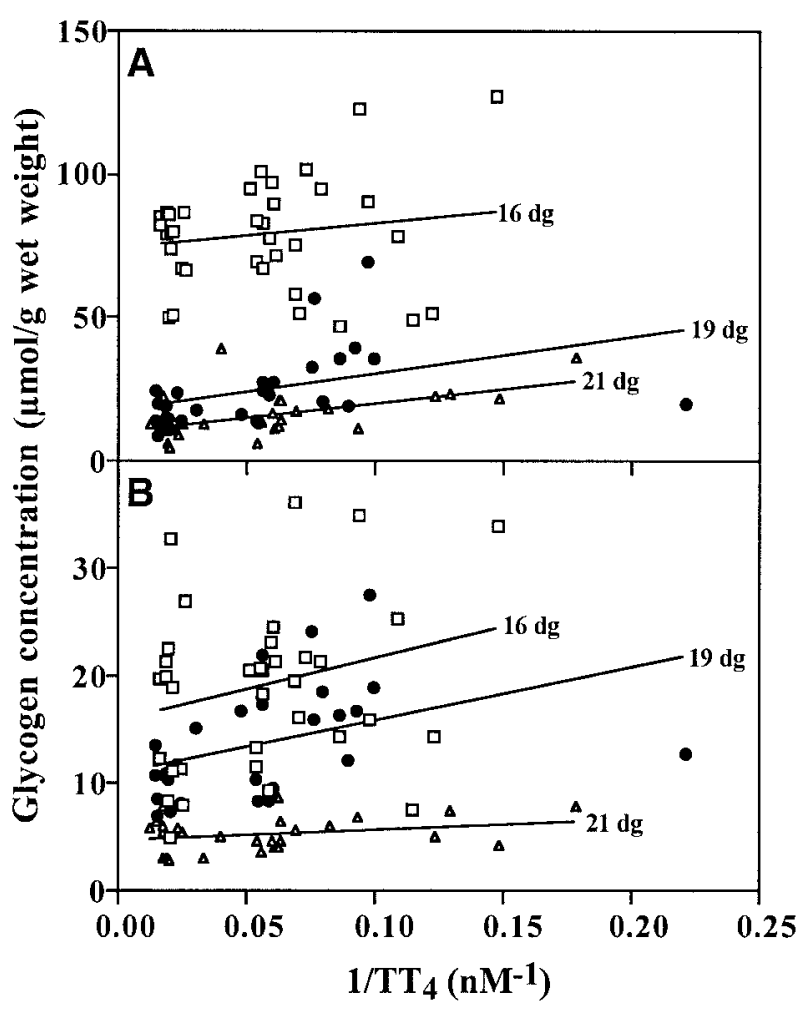

Figure 3 Relationship between placental glycogen concentration and pre-mating maternal serum $\mathrm{TT}_{4}$ levels. Data are derived from $\mathrm{N}$ and TX dams at 16 d.g. ( $\square), 19$ d.g. $(\circlearrowleft)$ and 21 d.g. $(\triangle)$. (A) Regression of the glycogen concentration in the maternal side of the placenta on the reciprocal of $\Pi_{4}$ yields significant relationships at 19 d.g. $(r=0.411 ; P=0 \cdot 030 ; n=28)$ and at 21 d.g. $(r=0.543 ; P=0.004 ; n=27)$ of similar slope (pooled slope $=113.4)$ but different $(P=0.003)$ elevation. (B) Regression of the glycogen concentration in the fetal side of the placenta on the reciprocal of $\Pi_{4}$ yields a significant relationship at 19 d.g. only (slope $=49 \cdot 7 \pm$ $21 \cdot 4 ; r=0 \cdot 415 ; P=0 \cdot 028 ; n=28)$.

This resulted in the selection of a one-factor multiple regression model $(R=0.671 ; P=0.003)$ in which fetal body weight was related only to the reciprocal of premating maternal serum $\mathrm{TT}_{4}$. Consequently, maternal and/or placental glucose metabolic compromise are unlikely to contribute to fetal growth retardation in hypothyroid pregnancies near term.

\section{Discussion}

We have studied rat dams thyroidectomized several weeks before pregnancy and shown that the impact on fetal growth varies according to the severity of maternal hypothyroidism, the stage of pregnancy and the fetal tissue under study. Moderate hypothyroidism (pre-mating maternal serum $\mathrm{TT}_{4}>16.19 \mathrm{nM}$ ) was associated with transient reductions in fetal body and brain weights before the onset of fetal thyroid hormone secretion, and a
Table 4 Serum and amniotic fluid glucose levels in $N, T_{m}$ and $\mathrm{TX}_{\mathrm{s}}$ dam pregnancies

\begin{tabular}{|c|c|c|c|c|}
\hline & Dam & $\begin{array}{l}\text { Maternal serum } \\
(\mathrm{mM})\end{array}$ & $\begin{array}{l}\text { Fetal serum } \\
(\mathrm{mM})\end{array}$ & $\begin{array}{l}\text { Amniotic fluid } \\
(\mathrm{mM})\end{array}$ \\
\hline 16 d.g. & $\begin{array}{l}\mathrm{N} \\
\mathrm{TX}_{\mathrm{m}} \\
\mathrm{TX}_{\mathrm{s}}\end{array}$ & $\begin{array}{l}7 \cdot 02 \pm 0 \cdot 28 \\
7 \cdot 04 \pm 0 \cdot 28 \\
6 \cdot 91 \pm 0 \cdot 19\end{array}$ & $\begin{array}{l}2 \cdot 23 \pm 0 \cdot 11 \\
1 \cdot 89 \pm 0 \cdot 18 \\
1 \cdot 83 \pm 0 \cdot 13\end{array}$ & $\begin{array}{l}4 \cdot 10 \pm 0 \cdot 16 \\
3 \cdot 67 \pm 0 \cdot 18^{\mathrm{a}} \\
3 \cdot 46 \pm 0 \cdot 05^{\mathrm{b}}\end{array}$ \\
\hline 19 d.g. & $\begin{array}{l}\mathrm{N} \\
\mathrm{TX}_{\mathrm{m}} \\
\mathrm{TX}_{\mathrm{s}}\end{array}$ & $\begin{array}{l}6 \cdot 29 \pm 0 \cdot 20 \\
6 \cdot 04 \pm 0 \cdot 23 \\
6 \cdot 32 \pm 0 \cdot 21\end{array}$ & $\begin{array}{l}1 \cdot 40 \pm 0 \cdot 13 \\
1 \cdot 37 \pm 0 \cdot 18 \\
1 \cdot 28 \pm 0 \cdot 09\end{array}$ & $\begin{array}{l}2 \cdot 04 \pm 0 \cdot 18 \\
1 \cdot 89 \pm 0 \cdot 10 \\
1 \cdot 90 \pm 0 \cdot 13\end{array}$ \\
\hline 21 d.g. & $\begin{array}{l}\mathrm{N} \\
\mathrm{TX}_{\mathrm{m}} \\
\mathrm{TX}_{\mathrm{s}}\end{array}$ & $\begin{array}{l}5 \cdot 75 \pm 0 \cdot 23 \\
5 \cdot 78 \pm 0 \cdot 48 \\
5 \cdot 56 \pm 0 \cdot 33\end{array}$ & $\begin{array}{l}5 \cdot 06 \pm 0 \cdot 26 \\
4 \cdot 30 \pm 0 \cdot 49 \\
3 \cdot 56 \pm 0 \cdot 25^{b}\end{array}$ & \\
\hline
\end{tabular}

a $P<0.05$ and ${ }^{\mathrm{b}} \mathrm{P}<0.001 \mathrm{TX}_{\mathrm{m}}$ or $\mathrm{TX}_{\mathrm{s}} \mathrm{vs} \mathrm{N}$ dam; $n \geq 12$ different pregnancies for maternal serum, $n \geq 6$ different pregnancies for fetal serum and $n \geq 4$ different pregnancies for amniotic fluid. Rat amniotic fluid at $21 \mathrm{~d}$.g. is very viscous and was not collected.

reduction in fetal liver weight near term. In contrast, more severe hypothyroidism was associated with deficits in fetal body, brain and liver weights which were more pronounced and asymmetrical near term; fetal liver weight was more markedly reduced than body weight, whereas some brain growth-sparing occurred. These findings are in agreement with earlier studies of dams made hypothyroid before pregnancy (Morreale de Escobar et al. 1985, Pickard et al. 1999). We hypothesized that maternal and placental glycogen storage and glucose supply to the fetus are disturbed in TX dams, and that such glucose metabolic compromise contributes to fetal growth retardation, especially near term, when the fetal demand for glucose is high.

Thyroidectomy of rat dams on the day of conception impairs the build-up of the maternal metabolic stores, including liver glycogen, required to support late fetal growth. Maternal hypoglycemia may (Bonet \& Herrera 1991) or may not (Porterfield et al. 1975) ensue, however fetal and placental growth is severely retarded in late gestation (Bonet \& Herrera 1988, Hendrich \& Porterfield 1992). In contrast, in the present study, maternal liver glycogen concentration was elevated in $\mathrm{TX}_{\mathrm{s}}$ dams at 16 and $19 \mathrm{~d} . \mathrm{g}$. This increase was partly related to pre-mating maternal thyroid status, in keeping with studies in thyroidectomized non-pregnant adult animals (Tata et al. 1963, Castro \& Herrera 1973) and was also related to litter size, which was depressed in TX dams. Importantly, maternal euglycemia was maintained in $\mathrm{TX}_{\mathrm{s}}$ dams, perhaps due to the establishment of compensatory metabolic mechanisms before exposure to the stress of pregnancy, and to the depression in litter size and thus feto-placental metabolic demands.

Rat placental glycogen stores are depleted by chronic $\mathrm{T}_{3}$ administration in late gestation (Shafrir et al. 1994). In agreement with this finding, placental glycogen 


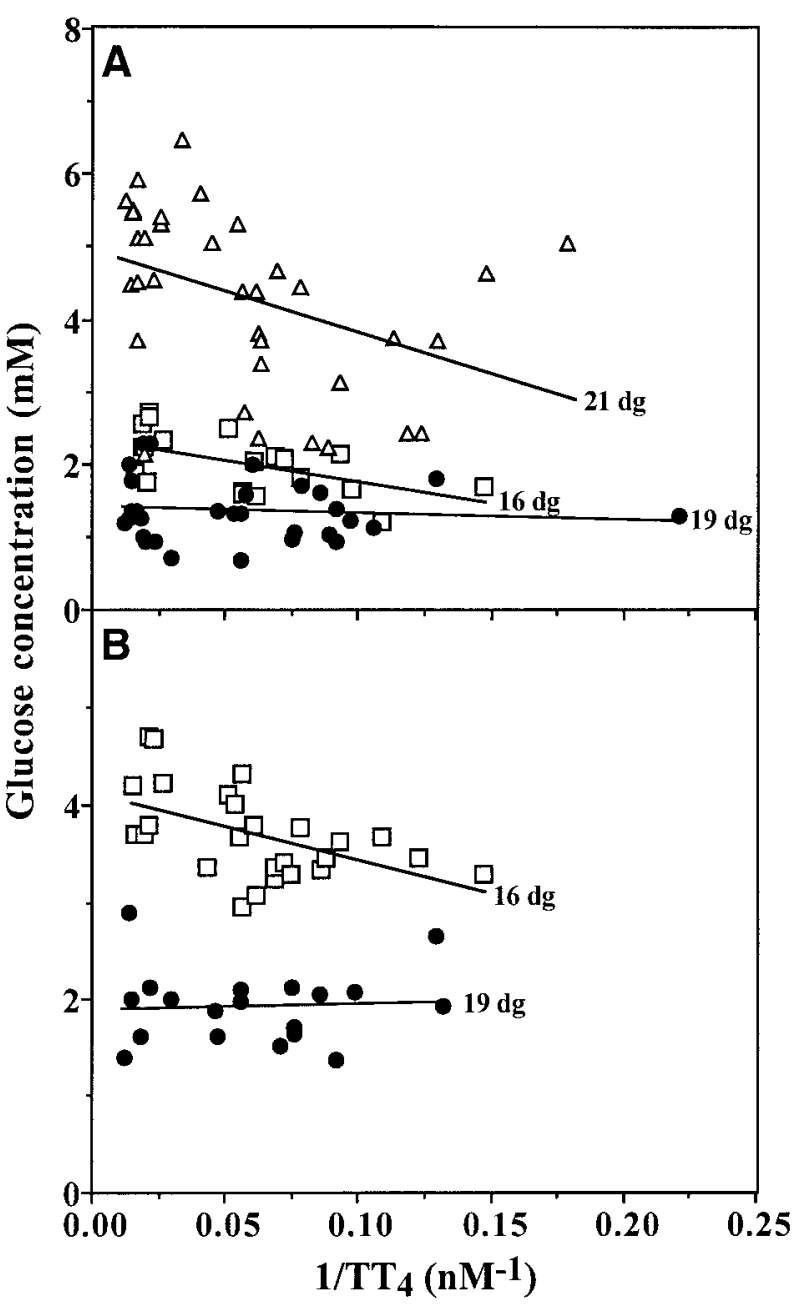

Figure 4 Relationship between fetal glucose levels and pre-mating maternal serum $T_{4}$. Data are derived from $\mathrm{N}$ and TX dams at 16 d.g. ( $\square$ ), 19 d.g. ( $)$ and 21 d.g. ( $\triangle$ ). (A) Regression of fetal serum glucose levels on the reciprocal of $\Pi_{4}$ yields significant relationships at 16 d.g. $(r=-0.551 ; P=0.010 ; n=21)$ and 21 d.g. $(r=-0.402 ; P=0.017 ; n=35)$. (B) Regression of amniotic fluid glucose levels on the reciprocal of $\mathrm{TT}_{4}$ yields a significant relationship at 16 d.g. $(r=-0.522 ; P=0.006 ; n=26)$.

concentration was elevated in $\mathrm{TX}_{\mathrm{s}}$ dams: at 19 and 21 d.g. in the maternal side, but at 16 and 19 d.g. in the fetal side, independent of reduced fetal size. These differences may be cell specific, since glycogen is predominantly found in glycogen cells and syncytiotrophoblasts on the maternal and fetal sides respectively (Davies \& Glasser 1968, Ne'eman et al. 1987). Placental thyroid hormone homeostasis may also be influential since, in hypothyroid dams, the $T_{3}: T_{4}$ ratio is increased on the maternal side, whereas fetal thyroid function compensates thyroid hormone deficits on the fetal side (Ruiz de Ona et al. 1991, Calvo et al. 1992). Thyroidectomy of pregnant dams, in contrast, causes no elevation in term placental glycogen levels (Porterfield et al. 1975), perhaps due to the attendant severe maternal metabolic and placental growth compromise.

At 16 d.g., fetal serum and amniotic fluid glucose levels exhibited similar dependencies on pre-mating maternal serum $\mathrm{TT}_{4}$, but only the amniotic fluid glucose level was reduced in $\mathrm{TX}_{\mathrm{m}}$ and $\mathrm{TX}_{\mathrm{s}}$ dams. Previously, fetal serum glucose was found to be depressed in moderately hypothyroid dams at 16 d.g. (Pickard et al. 1999). The reason for this discrepancy is unclear, but current findings indicate that fetuses of TX dams exhibit at worst only mild hypoglycemia prior to the onset of fetal thyroid function. At 19 d.g., fetal serum and amniotic fluid glucose concentrations had normalized in $\mathrm{TX}_{\mathrm{m}}$ and $\mathrm{TX}_{\mathrm{s}}$ dams, but fetal liver glycogen stores were deficient. At 21 d.g., these normalized in $\mathrm{TX}_{\mathrm{m}}$ dams, whereas they remained deficient in $\mathrm{TX}_{\mathrm{s}}$ dams, and this was accompanied by severe fetal hypoglycemia. Deficient liver glycogen storage coupled with hypoglycemia is also characteristic of term fetuses from dams thyroidectomized soon after conception (Porterfield et al. 1975). In our model at least, such effects were strongly related to fetal body weight, pre-mating maternal serum $\mathrm{TT}_{4}$ having no residual influence.

The relationship between fetal body weight and serum glucose may indicate that fetal body weight is strongly constrained by fetal serum glucose or, alternatively, that the ontogenic increase in fetal serum glucose concentration is dependent on some uncharacterized factor related to fetal growth. The data analysis presented here cannot discriminate unambiguously between these possibilities, since the statistical approach used does not allow mechanistic conclusions to be made definitively. The second possibility is perhaps more likely to occur in this model however, since the maternal serum glucose concentration and placental expression of GLUT protein isoforms (Pickard et al. 1999) are normal in TX dams near term, albeit materno-fetal glucose transport remains to be determined. Thus fetal growth retardation in $\mathrm{TX}_{\mathrm{s}}$ dams at this stage is unlikely to be due to impaired fetal glucose availability or maternal/placental glucose metabolic compromise. Indeed, maternal liver and placental glycogen concentrations and maternal serum glucose were all rejected as predictor variables for fetal body weight at 21 d.g. in the multiple regression analysis. This was not unexpected for maternal liver glycogen and serum glucose levels, since both were normal in $\mathrm{TX}_{\mathrm{s}}$ dams at $21 \mathrm{~d}$.g. A role for maternal glucose metabolic compromise in fetal growth retardation in $\mathrm{TX}_{\mathrm{s}}$ dams at earlier stages of pregnancy is also unlikely, since fetal body weight at 16 and 19 d.g. was unrelated to maternal serum glucose (data not shown) and hepatic glycogen concentrations.

More general disturbances in maternal metabolism may contribute to fetal growth retardation in TX dams, since hypothyroidism during pregnancy impairs maternal body weight gain (Bonet \& Herrera 1988, Versloot et al. 1998). This did not appear to occur in the present study, since 
although maternal carcass weight (after removal of uteri) tended to be slightly lower (by 10\%) for $\mathrm{TX}_{\mathrm{m}}$ and $\mathrm{TX}_{\mathrm{s}}$ dams compared with $\mathrm{N}$ dams at 16 and $21 \mathrm{~d}$.g. (data not shown), it had no influence on fetal growth in single or multiple regression analyses with other relevant factors (data not shown). Furthermore, maternal nutritional restriction depresses placental weight and glycogen stores (Woodall et al. 1996, Rudge et al. 1999), whereas the TX dams in the present study exhibited normal placental weight and elevated placental glycogen stores.

In conclusion, fetal body weight during late gestation exhibits a hyperbolic relationship with pre-mating maternal serum $\mathrm{TT}_{4}$ levels in rat dams made hypothyroid before conception; permanent fetal growth retardation occurring only in severely hypothyroid dams. In such pregnancies, excessive glycogen storage occurs in the maternal liver and the placenta from before the onset of fetal thyroid function, whereas fetal liver glycogen stores and serum glucose levels are depressed near term. These fetal deficits appear due to the attendant fetal growth retardation, and neither maternal nor placental glucose metabolic compromise are likely to contribute to this process near term. The mechanisms by which severe maternal hypothyroidism retard fetal growth near term remain to be determined.

\section{References}

Altman DG \& Gardner MJ 1989 Calculating confidence intervals for regression and correlation. In Statistics with Confidence, pp 34-49. Eds MJ Gardner \& DG Altman. London: BMJ Books.

Bonet B \& Herrera E 1988 Different response to maternal hypothyroidism during the first and second half of gestation in the rat. Endocrinology 122 450-455.

Bonet B \& Herrera E 1991 Maternal hypothyroidism during the first half of gestation compromises normal catabolic adaptations of late gestation in the rat. Endocrinology 129 210-216.

Calvo R, Obregon MJ, Escobar del Rey F \& Morreale de Escobar G 1992 The rat placenta and the transfer of thyroid hormones from the mother to the fetus. Effects of maternal thyroid status. Endocrinology 131 357-365.

Castro M \& Herrera E 1973 Effect of thyroidectomy on circulating components and liver metabolism in fed and fasted rats. Hormone Research 4 357-366.

Davies J \& Glasser SR 1968 Histological and fine structural observations on the placenta of the rat. Acta Anatomica 69 542-608.

Girard J, Ferré P, Pégorier J-P \& Duée P-H 1992 Adaptations of glucose and fatty acid metabolism during perinatal period and suckling-weaning transition. Physiological Reviews 72 507-562.

Gruppuso PA \& Brautigan DL 1989 Induction of hepatic glycogenesis in the fetal rat. American Journal of Physiology 256 E49-E54.

Hendrich CE \& Porterfield SP 1992 Serum growth hormone levels in hypothyroid and $\mathrm{GH}$-treated thyroidectomized rats and their progenies. Proceedings of the Society for Experimental Biology and Medicine 201 296-302.

Jones CT \& Rolph TP 1985 Metabolism during fetal life: a functional assessment of metabolic development. Physiological Reviews $\mathbf{6 5}$ $357-430$.
Keppler D \& Decker K 1984 Glycogen. In Methods of Enzymatic Analysis, vol VI, pp 11-18. Eds HU Bergmeyer, J Bergmeyer \& M Grassl. Weinheim: Verlag Chemie.

Leonard AJ, Pickard MR, Sinha AK, Edwards PR, Evans IM \& Ekins RP 1999 Maternal thyroid dysfunction and c-fos and c-jun expression in rat placenta. Placenta 20 727-731.

Leonard AJ, Evans IM, Pickard MR, Bandopadhyay R, Sinha AK \& Ekins RP 2001 Thyroid hormone receptor expression in rat placenta. Placenta 22 353-359.

Morreale de Escobar G, Pastor R, Obregón MJ \& Escobar del Rey F 1985 Effects of maternal hypothyroidism on the weight and thyroid hormone content of rat embryonic tissues, before and after onset of fetal thyroid function. Endocrinology 117 1890-1900.

Morreale de Escobar G, Obregón MJ \& Escobar del Rey F 2000 Is neuropsychological development related to maternal hypothyroidism or to maternal hypothyroxinemia? Endocrine Reviews 85 3975-3987.

Ne'eman Z, Barash V, Rosenmann E \& Shafrir E 1987 Localization of glycogen in the placenta of diabetic rats: a light and electron microscopic study. Placenta 8 201-208.

Pickard MR, Evans IM, Bandopadhyay R, Leonard AJ, Sinha AK \& Ekins RP 1997 Thyroid hormone action in rat brain from fetal to adult life. In Recent Research Developments in Neuroendocrinology Thyroid Hormone and Brain Maturation, pp 15-29. Ed. CE Hendrich. Trivandrum: Research Signpost.

Pickard MR, Sinha AK, Ogilvie L, Leonard AJ, Edwards PR \& Ekins RP 1999 Maternal hypothyroxinemia influences glucose transporter expression in fetal brain and placenta. Journal of Endocrinology 163 385-394.

Porterfield SP \& Hendrich CE 1993 The role of thyroid hormones in prenatal and neonatal neurological development - current perspectives. Endocrine Reviews 14 94-106.

Porterfield SP, Whittle E \& Hendrich CE 1975 Hypoglycemia and glycogen deficits in fetuses of hypothyroid pregnant rats. Proceedings of the Society for Experimental Biology and Medicine 149 748-753.

Rudge MV, Gomes CM, Calderon Ide M, Ramos MD, Abbade JF, de Oliveira MG \& da Silva MG 1999 Study of the evolution of the placenta and fetal pancreas in the pathophysiology of growth retardation intrauterine due to restricted maternal diet. Sao Paulo Medical Journal 117 49-56.

Ruiz de Ona C, Morreale de Escobar G, Calvo R, Escobar del Rey F \& Obregón MJ 1991 Thyroid hormones and 5'-deiodinase in the rat fetus late in gestation: effects of maternal hypothyroidism. Endocrinology 128 422-432.

Shafrir E \& Barash V 1991 Placental glycogen metabolism in diabetic pregnancy. Israel Journal of Medical Sciences 27 449-461.

Shafrir E, Barash V, Zederman R, Kissilevitz R \& Diamant YZ 1994 Modulation of fetal and placental metabolic pathways in response to maternal thyroid and glucocorticoid hormone excess. Israel Journal of Medical Sciences 30 32-41.

Tata JR, Ernster L, Lindberg O, Arrhenius E, Pedersen S \& Hedman R 1963 The action of thyroid hormones at the cell level. Biochemical Journal 86 408-428.

Versloot PM, van der Heide D, Schröder-van der Elst JP \& Boogerd L 1998 Maternal thyroxine and 3,5,3'-tri-iodothyronine kinetics in near-term pregnant rats at two different levels of hypothyroidism. European Journal of Endocrinology 138 113-119.

Woodall SM, Breier BH, Johnston BM \& Gluckman PD 1996 A model of intrauterine growth retardation caused by chronic maternal undernutrition in the rat: effects on the somatotropic axis and postnatal growth. Journal of Endocrinology 150 231-242.

Received in final form 21 October 2002 Accepted 31 October 2002 